\title{
DA INSEMINAÇÃO ARTIFICIAL HOMÓLOGA POST MORTEM SOB A ÓTICA DO DIREITO À FILIAÇÃO E À SUCESSÃO
}

\author{
Valéria Silva Galdino Cardin ${ }^{1}$ \\ Caio Eduardo Costa Cazelatto ${ }^{2}$ \\ Mylene Manfrinato dos Reis ${ }^{3}$
}

\begin{abstract}
RESUMO: A presente pesquisa analisou, por meio da revisão bibliográfica, o direito à filiação e a sucessão da prole concebida pelas técnicas de reprodução humana assistida post mortem, sobretudo ao que se refere à possibilidade de o mesmo habilitar-se como herdeiro legítimo do patrimônio deixado por seu idealizador. O Código Civil é inconsistente na abordagem do tema, já que reconhece a esses indivíduos o direito à presunção de parentalidade, mas silencia-se quanto a sua capacidade de suceder na forma legítima, preconizando tão somente a sucessão na modalidade testamentária, o que abre espaço para discussões jurídicas em contrapondo a segurança jurídica do sistema sucessório e do direito à igualdade dos filhos, entre outros princípios do Direito de Família. Assim, observou-se necessidade de se ter regras claras que contemplem o direito sucessório das crianças advindas das técnicas de reprodução humana assistida post mortem, buscando não apenas uniformizar e esclarecer as controvérsias que permeiam o tema, mas de oferecer a estas o devido amparo estatal.
\end{abstract}

PALAVRAS-CHAVE: Direito Sucessório; Filiação; Post mortem; Reprodução humana assistida; Sucessão.

\section{INTRODUÇÃO}

As novas técnicas de reprodução assistida são um meio de concretização do direito fundamental ao planejamento familiar, na medida que auxiliam/solucionam determinados problemas correlatos com a esterilidade e/ou infertilidade de seu(s) titular(res). Um dos mecanismos de exercer o referido direito pode ocorrer por meio da inseminação artificial após a morte daquele(s) que idealizaram o projeto parental, sendo denominado como reprodução humana assistida post mortem, que se divide nas modalidades homóloga, que é a técnica que se

\footnotetext{
${ }^{1}$ Pós-doutora em Direito pela Universidade de Lisboa; Doutora e mestre em Direito das Relações Sociais pela Pontifícia Universidade Católica de São Paulo (PUCSP); Docente da Universidade Estadual de Maringá e no Programa de Pós-graduação em Ciências Jurídicas pelo Centro Universitário de Maringá (UNICESUMAR); Pesquisadora pelo ICETI; Advogada no Paraná; E-mail: < valeria@galdino.adv.br>.

2 Mestre em Ciências Jurídicas pelo Centro Universitário de Maringá (Unicesumar); Bacharel em Direito pela Universidade Estadual de Maringá (UEM); Docente do Centro Universitário Ingá (Uningá); Membro do Centro de Investigação Jurídico-Económica (CIJE) da Faculdade de Direito da Universidade do Porto (FDUP); Advogado no Paraná. Brasil. E-mail: caio.cazelatto@hotmail.com

${ }^{3}$ Mestranda em Ciências Jurídicas pelo Centro Universitário de Maringá (Unicesumar); Bacharela em Direito pelo Centro Universitário de Maringá (Unicesumar); Membra do núcleo de pesquisa Direitos da Personalidade e seu Alcance na Contemporaneidade, do CNPQ. Brasil. E-mail: leny_my@hotmail.com
} 
utiliza os materiais genéticos dos cônjuges/companheiros, e heteróloga, que é aquela em que se adota um dos gametas de um terceiro doador.

São nestes casos que o tema ganha maior relevância, tendo em vista que a legislação brasileira é vaga em sua regulamentação, deixando a cargo das Resoluções do Conselho Federal de Medicina indicar a viabilidade e a responsabilidade administrativa desses procedimentos, o que inevitavelmente gera controvérsias, principalmente, na esfera jurídica. Para a sua melhor compreensão, foi examinado o instituto da filiação e sua evolução no ordenamento jurídico brasileiro, dando enfoque à promulgação da Constituição Federal de 1988 e ao Código Civil atual, destacando-se os princípios e as características que norteiam hodiernamente o instituto da filiação advindo do emprego da técnica de inseminação artificial post mortem.

Posteriormente, foi investigada a reprodução humana assistida, abordando a sua definição, classificação e consequências, especialmente ao que corresponde à inseminação artificial homóloga e heteróloga e a maternidade substitutiva. Nessa perspectiva, foram observadas as normas que a sucessão, explicitando as espécies existentes, o momento da abertura da sucessão e a vocação hereditária, passando então ao delineamento do tratamento sucessório dado à prole eventual $\mathrm{e}$, a análise da possibilidade dos filhos concebidos por inseminação post mortem herdarem tanto por testamento, como legitimamente os bens deixados por seu progenitor.

Para tanto, o presente trabalho foi desenvolvido por meio do método teórico, a partir da revisão bibliográfica, a qual consiste na separação, leitura e coleta de dados de artigos, livros, jurisprudências e trabalhos científicos relacionados com o direito à filiação e o direito sucessório do filho concebido post mortem, em especial, no que se refere à possibilidade do mesmo habilitarse como herdeiro legítimo do patrimônio deixado por seu idealizador.

\section{DA EVOLUÇÃO DO INSTITUTO DA FILIAÇÃO NO ORDENAMENTO JURÍDICO BRASILEIRO}

Até a promulgação da Constituição Federal de 1988, restou-se assentado no ordenamento jurídico brasileiro o tratamento diferenciado entre os filhos, de acordo com sua origem. Assim, a prole era classificada em legítimos e ilegítimos, em que estes últimos tinham diversos direitos e garantias negados por serem fruto de relacionamentos extraconjugais (DIAS, 2015, p. 387). Entre os anos de 1603 e 1916, por exemplo, esteve vigente no Brasil as Ordenações 
Filipinas $^{4}$, simultaneamente com algumas leis extravagantes, as quais previam expressamente esse trato discriminatório.

Sob a perspectiva sucessória, Márcio Antonio Boscaro leciona que na mencionada legislação era:

[...] marcante era a diferenciação entre filho legítimo e ilegítimo. Admitia-se o reconhecimento do filho ilegítimo, permitindo-se a sucessão testamentária, mas nunca a legítima. Já os filhos naturais concorriam com os legítimos à herança e, somente na falta de todos os filhos legítimos é que os ilegítimos teriam o direito. Com relação à investigação de paternidade, os filhos espúrios podiam somente pleitear se fosse caso de alimentos (BOSCARO, 2002, p. 61).

A Proclamação da Independência, em 07 de setembro de 1822, levou ao surgimento da Constituição Imperial de 1824, outorgada por D. Pedro I, que entre os seus dispositivos instituiu o princípio da igualdade de todos perante a lei (DEIRÓ, 2006), consequentemente, houve a abolição das distinções e privilégios legais que desfrutavam os filhos legítimos dos nobres ${ }^{5} \mathrm{em}$ detrimentos dos ilegítimos (SOUSA; BRITO, 2011, p. 130-135).

Já no ano de 1847 foi promulgado o Decreto-lei n 463 , o qual previu o fim da distinção entre os filhos para fins sucessórios. Nessa oportunidade, os filhos ilegítimos passaram a ter os mesmos direitos assegurados aos filhos naturais ${ }^{6}$, desde que reconhecidos pelo pai por meio de escritura pública ou testamento ${ }^{7}$, requisito este indispensável para que pudesse suceder ${ }^{8}$.

Após o advento da Proclamação da República, houve a promulgação do Código Civil de 1916, que conforme será melhor delineado a frente, trouxe retrocessos no que se refere aos filhos ilegítimos, assim, acabou-se "com a possibilidade de reconhecimento dos filhos espúrios" e estabeleceu-se "distinções entre os filhos legítimos e ilegítimos, tendo como base o fato dos pais serem ou não casados entre si” (BOSCARO, 2002, p. 63), o que representou um verdadeiro colapso para os direitos dos filhos havidos fora do casamento, que novamente se viram privados da proteção e de direitos exclusivamente em razão da sua origem.

\subsection{A FILIAÇÃO NO CÓDIGO CIVIL DE 1916 E EM LEIS ESPARSAS}

\footnotetext{
${ }^{4}$ As ordenações constituíam compilações de leis e costumes.

${ }^{5}$ As Ordenações Filipinas faziam distinção entre filhos ilegítimos de nobres e filhos ilegítimos de plebeus, já que estes últimos tinham assegurado o direito à herança paterna, enquanto os primeiros somente poderiam herdar quando legitimados pelo Rei ou pelo Desembargo do Paço. (SOUSA; BRITO, 2011, p. 130-135).

6 "Art. $1^{\circ}$ Aos filhos naturaes dos nobres ficão extensivos os mesmos direitos hereditarios, que, pela Ordenação livro quarto, título noventa e dous, competem aos filhos naturaes plebeos."

7 “Art. $2^{\circ} \mathrm{O}$ reconhecimento do pai, feito por escriptura publica, antes do seu casamento, he indispensavel para que qualquer filho natural possa ter parte na herança paterna, concorrendo elle com filhos legitimos do mesmo pai.

${ }^{8}$ Art. $3^{\circ}$ A prova de filiação natural, nos outros casos, só se poderá fazer por hum dos seguintes meios; escriptura publica, ou testamento."
} 
O Código Civil de 1916 estipulava que apenas a família constituída pelo casamento era reconhecida pelo Estado, sendo que no que concerne especificamente ao instituto da filiação persistiu a distinção entre os filhos havidos na constância do matrimônio e os filhos adulterinos, de modo que "a situação conjugal do pai e da mãe se refletia na identificação dos filhos: conferialhes ou subtraía-lhes não só o direito à identidade, mas também o direito à sobrevivência" (DIAS, 2015, p. 387).

Frisa-se que os chamados filhos legítimos consistiam naqueles concebidos na constância do casamento, mesmo que este posteriormente fosse anulado ou até mesmo considerado nulo, conforme preconizava os artigos $337^{9}$ e $353^{10}$, ambos do Código Civil de 1916, já os filhos ilegítimos eram assim identificados por terem sido concebidos fora do casamento ou por pessoas solteiras (DIAS, 2015).

A respeito da classificação dos filhos, conforme sua origem, Caio Mário da Silva Pereira sustenta que:

[...] os ilegítimos eram os que provinham de relações sexuais entre pessoas não casadas, e subdividia-se em naturais e espúrios. Os filhos ilegítimos naturais eram os concebidos por pessoas não casadas e desimpedidas. Já os espúrios são aqueles cujos pais estão impedidos de casar em razão de estarem casados com terceiros. Caso o impedimento decorra de parentesco próximo, os filhos eram classificados como ilegítimos incestuosos (PEREIRA, 2012, p. 318).

Observa-se que uma maior discriminação circundava os filhos oriundos de relações adulterinas ou incestuosas, já que nos termos do artigo $358^{11}$ do Código Civil de 1916, esses indivíduos sequer poderiam ser reconhecidos.

Há nesta época a supervalorização do instituto do matrimônio, de tal modo que as normas jurídicas, até então vigentes, tinham como único objetivo a preservação da família constituída pelo casamento, tanto é que se admitia a marginalização do filho oriundo de relações extraconjugais, em favor de um bem maior, que seria a manutenção da paz social do lar formado pelo genitor (DIAS, 2015, p. 387). Tais são reflexos do:

[...] sentimento dominante na sociedade de então, no sentido de preservar a família fundada no matrimônio e de resguardar esse instituto contra ameaças externas, cuja expressão máxima seria o reconhecimento de um filho gerado por um dos cônjuges, com terceira pessoa (BOSCARO, 2002, p. 65).

\footnotetext{
9 "São legítimos os filhos concebidos na constancia do casamento, ainda que anulado (art. 217), ou mesmo nulo, se se contraiu de boa fé (art. 221)."

10 "A legitimação resulta do casamento dos pais, estando concebido, ou depois de havido o filho."

11 "Os filhos incestuosos e os adulterinos não podem ser reconhecidos." 
Com o passar do tempo, surgiram as Leis $\mathrm{n}^{\circ} 4.737$ e 4.883 , promulgadas em $1942 \mathrm{e}$ 1949 respectivamente, que autorizaram o reconhecimento dos filhos concebidos fora do matrimônio, porém apenas após a dissolução do casamento do progenitor ${ }^{12}$, bem como assegurou o direito de investigação de paternidade com o objetivo de se pleitear alimentos. Ressalta-se que, mesmo diante das inovações legais trazidas, os filhos continuaram a ser registrados como ilegítimos e, fazendo jus a apenas a metade da herança recebida pelos filhos legítimos ou legitimados (DIAS, 2015, p. 388).

Foi a Lei ${ }^{\circ}$ 6.515/77, também conhecida como Lei do Divórcio, responsável por garantir a os filhos o direito à herança em igualdade de condições, bem como admitiu o reconhecimento, ainda na constância do casamento, do filho havido fora do casamento por meio de testamento cerrado ${ }^{13}$, além de resguardar a legitimidade e os direitos civis aos filhos havidos de casamento nulo ou anulável, mesmo que ambos os cônjuges não o tivessem contraído de boafé eram considerados legítimos (WELTER, 2003).

No ano de 1988, grandes avanços foram alcançados com a promulgação da Constituição Federal, consagrou-se a convivência familiar como um direito fundamental e adotou-se a proteção integral em relação à criança e ao adolescente, que foram elevados ao status de sujeitos de direitos, fatos que promoveram uma verdadeira revolução na identificação dos vínculos familiares e, no próprio Direito de Família e seus institutos (DIAS, 2015, p. 388), ao passo que novos princípios passaram a orientar sua aplicação, visando atender as novas demandas sociais.

\subsection{DOS PRINCÍPIOS CONSTITUCIONAIS DIRECIONADOS AO DIREITO DE FILIAÇÃO}

A nova ordem constitucional direcionou maior atenção tanto ao indivíduo, como à sociedade, consagrando em seu bojo uma série de direitos individuais e coletivos (SILVA, 2018).

Já que além de reconhecer a família como base da sociedade, por exemplo, preconizou ainda a igualdade no seio familiar, tanto entre os cônjuges, como entre os filhos, independentemente da sua origem (COMEL, 2003) e a liberdade para o planejamento familiar.

O princípio da isonomia encontra respaldo no caput do artigo $5^{\mathrm{ol4}}$ da Constituição Federal, que enuncia que todos os indivíduos são iguais perante a lei brasileira, vedando nos

\footnotetext{
${ }^{12} \mathrm{O}$ artigo $1^{\circ}$ da Lei $\mathrm{n}^{\circ} 883$, de 21 de outubro de 1949, preconizava o seguinte: "dissolvida a sociedade conjugal, será permitido a qualquer dos cônjuges o reconhecimento do filho havido fora do matrimônio e, ao filho a ação para que se lhe declare a filiação". (BRASI, 1949).

${ }^{13}$ A Lei $\mathrm{n}^{\circ} 6.515 / 77$ alterou o artigo $1^{\circ}$ da Lei $\mathrm{n}^{\circ} 883 / 49$, acrescentando o parágrafo único nos seguintes termos: "Ainda na vigência do casamento qualquer dos cônjuges poderá reconhecer o filho havido fora do matrimônio, em testamento cerrado, aprovado antes ou depois do nascimento do filho, e, nessa parte, irrevogável".

14 “Art. $5^{\circ}$ Todos são iguais perante a lei, sem distinção de qualquer natureza, garantindo-se aos brasileiros e aos estrangeiros residentes no País a inviolabilidade do direito à vida, à liberdade, à igualdade, à segurança e à propriedade $[\ldots] "$.
} 
incisos subsequentes a discriminação por qualquer natureza. Dessa forma, a nova ordem constitucional busca assegurar a igualdade sob a perspectiva formal (igualdade na lei), bem como a perspectiva material (igualdade perante a lei) (SILVA, 2007), sendo que a primeira:

[...] constitui exigência destinada ao legislador, que na elaboração da lei, não poderá fazer nenhuma discriminação. Aliás, a lei punirá qualquer discriminação atentatória dos direitos e liberdades fundamentais (art. $\left.5^{\circ}, \mathrm{XLI}\right)$. A igualdade perante a lei pressupõe que esta já esteja elaborada e se traduz na exigência de que os Poderes Executivo e Judiciário, na aplicação da lei não façam qualquer discriminação (CHIMENTI, 2004).

A supremacia do princípio da igualdade alcançou todas as relações sociais, como uma espécie de ideal a ser alcançado, estendendo-se também ao Direito de Família, compreendendo os vínculos da filiação, à medida em que vedou qualquer designação discriminatória com relação aos filhos com base na relação dos seus progenitores (DIAS, 2015, p. 388) e garantiu os mesmos direitos e qualificações, nos termos do artigo 227, $\S 6^{\circ}$, da Constituição Federal, sendo dever da família, sociedade e Estado assegurar os mesmos direitos aos filhos advindos, do casamento ou adoção, sendo vedado qualquer forma de discriminação em relação a filiação.

Houve assim, a extinção por completo de qualquer tipo de prioridade proveniente da origem da filiação, que ressoou "tanto no campo patrimonial quanto no pessoal, não sendo admitida qualquer forma de distinção jurídica, sob as penas da lei", versando "na ótica familiar, da primeira e mais importante especialidade da isonomia constitucional". (TARTUCE, 2006).

Destaca-se que, em concordância com o princípio constitucional da prioridade absoluta, previsto no citado artigo 227, $\S 6^{\circ}$ da Constituição Federal, houve a promulgação do Estatuto da Criança e do Adolescente (Lei ${ }^{\circ}$ 8.069, de 13 de julho de 1990) (BRASIL, 1990), que se preocupou, nos mesmos termos constitucionais, em garantir o direito a filiação e igualdade entre filhos, nomeadamente nos artigos $20^{15}$ e $26^{16}$, assim como no Código Civil de 2002 em seu artigo $1.596^{17}$.

Assim, pode-se concluir que "juridicamente, todos os filhos são iguais perante a lei, havidos ou não durante o casamento" (TARTUCE, 2017, p. 784), uma vez que, com a promulgação da Constituição Federal de 1988 foi reconhecida a família gerada pelo casamento, pela união estável, pela homoafetividade, pela adoção e pela socioafetividade, o que

\footnotetext{
15 “Art. 1.596. Os filhos, havidos ou não da relação de casamento, ou por adoção, terão os mesmos direitos e qualificações, proibidas quaisquer designações discriminatórias relativas à filiação”.

16 "Art. 26. Os filhos havidos fora do casamento poderão ser reconhecidos pelos pais, conjunta ou separadamente, no próprio termo de nascimento, por testamento mediante escritura ou outro documento público, qualquer que seja a origem da filiação".

17 “Art. 1.596. Os filhos, havidos ou não da relação de casamento, ou por adoção, terão os mesmos direitos e qualificações, proibidas quaisquer designações discriminatórias relativas à filiação”.
} 
inevitavelmente coloca a prole advinda destes relacionamentos em uma mesma categoria, ou seja há igualdade entre "os filhos adotivos, os filhos socioafetivos e os havidos por inseminação artificial heteróloga (com material genético de terceiro)." (TARTUCE, 2017, p. 784).

Já o princípio do planejamento familiar foi consagrado tanto no artigo $226, \S 7^{\circ}$ da Constituição Federa $1^{18}$ quanto no artigo $1.565, \S 2^{\circ}$ do Código Civil ${ }^{19}$. Infraconstitucionalmente, esse princípio também se encontra regulamentado na Lei $n^{\circ} 9.263 / 1996$, que assegura o direito ao planejamento familiar, compreendido aqui como o conjunto de ações de regulação da fecundidade que garanta direitos iguais de constituição, limitação ou aumento da prole, a todo cidadão, independentemente de seu estado civil.

Ressalta-se que é nesse preceito que tanto a inseminação artificial, como a engenharia genética ganham embasamento legal, pois se por um lado a saúde sexual e reprodutiva desponta como requisito indispensável para a concretização do projeto de parentalidade, constituindo-se assim um direito fundamental, de outro os problemas concernentes à função reprodutora são encarados como questão de saúde pública, resguardando-se assim aos cidadãos o acesso ao tratamento de esterilidade e reprodução, como por exemplo, os métodos de reprodução assistida (DIAS, 2015, p. 388), a serem conceituados a frente.

\subsection{DA FILIAÇÃO NO CÓDIGO CIVIL DE 2002}

A Constituição Federal ao implementar uma nova ordem jurídica embasada não somente na liberdade e dignidade, mas também na igualdade, na solidariedade e na valorização da pessoa, inevitavelmente refletiu no âmbito do Direito de Família, ao passo que o Código Civil de 1916, que foi reflexo de uma sociedade predominantemente patriarcal e autoritária, passou a conflitar diretamente com aquela, levando à sua revogação, dada a impossibilidade de harmonização do mesmo com os novos preceitos constitucionais e seu desatendimento aos novos valores e anseios sociais (DIAS, 2015, p. 388).

O Código Civil de 2002, por sua vez, foi elaborado de acordo com os novos princípios constitucionais e, assim como na Constituição Federal, no que tange ao instituto da filiação, visando afastar qualquer resquício de discriminação entre os filhos em razão da origem,

\footnotetext{
18 “Art. 226. A família, base da sociedade, tem especial proteção do Estado. [...] $§ 7^{\circ}$ Fundado nos princípios da dignidade da pessoa humana e da paternidade responsável, o planejamento familiar é livre decisão do casal, competindo ao Estado propiciar recursos educacionais e científicos para o exercício desse direito, vedada qualquer forma coercitiva por parte de instituições oficiais ou privadas."

19 “Art. 1565. Pelo casamento, homem e mulher assumem mutuamente a condição de consortes, companheiros e responsáveis pelos encargos da família [...]. \$2 $2^{\circ}$ O planejamento familiar é de livre decisão do casal, competindo ao Estado propiciar recursos educacionais e financeiros para o exercício desse direito, vedado qualquer tipo de coerção por parte de instituições privadas ou públicas."
} 
consignou expressamente em seu artigo 1.596, os mesmos direitos entre estes independentemente de terem sido havidos fora do casamento ou concebidos na constância do matrimonio, não se admitindo mais também o uso das adjetivações discriminatórias (BRASIL, 2002).

Já o nascimento da criança continuou a estipular o vínculo jurídico entre os pais e o filho, em referência a citada presunção pater is est quem justae nuptiae demonstrant, sendo que a legislação vigente também manteve no capítulo concernente à filiação, especificamente no artigo $1.597^{20}$, as hipóteses em que se presumem terem os filhos sido concebidos na constância do casamento, já não mais para fins de configuração da filiação legítima, mas para a incidência da presunção legal de paternidade (DIAS, 2015, p. 388).

\subsection{DAS ESPÉCIES DE FILIAÇÃO: UM ENFOQUE NOS FILHOS NASCIDOS POR INSEMINAÇÃO ARTIFICIAL POST MORTEM}

Nos últimos anos, a família passou por intensas transformações conceituais, "deixando de ser unidade de caráter econômico, social e religioso para se afirmar fundamentalmente como grupo de afetividade e companheirismo" (DIAS, 2015, p. 389), diante desses novos contornos sociais, a doutrina e a jurisprudência em trabalho conjunto passaram a flexibilizar e ampliar a abrangência da lei, assim, hodiernamente, fala-se em filiação biológica, jurídica e/ou socioafetiva (TARTUCE, 2017, p. 784).

Sob a nova ordem instaurada, a filiação deixa de estar limitada exclusivamente ao aspecto biológico como outrora, podendo ser definida como a "relação de parentesco que se estabelece entre duas pessoas, uma das quais nascida da outra, ou adotada, ou vinculada mediante posse de estado de filiação ou por concepção derivada de inseminação artificial heteróloga" (LÔBO, 2011, p. 217), sendo que independentemente da origem terão estes os mesmos direitos.

Essa variedade de critérios para a fixação da filiação e paternidade, deve-se justamente ao enfraquecimento do caráter biológico e a ascensão da afetividade, enquanto ponto fulcral dos vínculos familiares, de tal modo que pouco importa a aplicação do direito se a filiação foi concebida de forma convencional, oriunda da adoção ou viabilizada por meio de técnicas de reprodução assistida, pois independentemente da origem usufruirão dos mesmos direitos e garantias sem qualquer tipo de diferenciação (DIAS, 2015, p. 390).

\footnotetext{
20 "Art. 1.597. Presumem-se concebidos na constância do casamento os filhos: I - nascidos cento e oitenta dias, pelo menos, depois de estabelecida a convivência conjugal; II - nascidos nos trezentos dias subsequentes à dissolução da sociedade conjugal, por morte, separação judicial, nulidade e anulação do casamento; III - havidos por fecundação artificial homóloga, mesmo que falecido o marido; IV - havidos, a qualquer tempo, quando se tratar de embriões excedentários, decorrentes de concepção artificial homóloga;

V - havidos por inseminação artificial heteróloga, desde que tenha prévia autorização do marido."
} 
Isso porque, como bem pontua Maria Berenice Dias, não mais interessa a origem da filiação, já que:

[...] os avanços científicos de manipulação genética popularizaram a utilização de métodos reprodutivos, como a fecundação assistida homóloga e heteróloga, a comercialização de óvulos e espermatozoides, a gravidez por substituição, e isso sem falar ainda na clonagem humana. Ditos avanços ocasionaram uma reviravolta nos vínculos de filiação. A partir do momento em que se tornou possível interferir na reprodução humana, por meio de técnicas laboratoriais, a procriação deixou de ser um fato natural para subjugar-se à vontade do homem (DIAS, 2015, p. 390).

Nesta esteira, partindo-se do pressuposto de que a filiação pode ser biológica, tendo como origem a consanguinidade, estabelecida pelos laços de sangue entre pais e filhos, bem como socioafetiva compreendendo aquela em que há relação de afeto, sem que haja um vínculo biológico, mostra-se possível atribuir a filiação ao indivíduo concebido por qualquer meio de reprodução humana assistida, observando os aspectos biológicos e/ou socioafetivo (MADALENO, 2004).

Vale salientar que, independentemente da técnica utilizada, os idealizadores do projeto parental constituídos por meio dos métodos de reprodução artificial, comprometem-se a prover à criança todas as condições necessárias para um desenvolvimento saudável, pois independentemente da utilização do seu material genético ou de terceiros (conforme o tipo de inseminação), a afetividade surge como critério determinante da filiação, podendo ou não se conjugar com o critério biológico (LÔBO, 2011).

No que se refere nomeadamente à inseminação artificial post mortem, o legislador brasileiro ao regrar o direito de filiação, no inciso III do citado artigo 1.597 do Código Civil, regulamentou presunção da paternidade dos filhos concebidos por meio de inseminação artificial homóloga na constância do casamento, ainda que ocorrida após a morte do seu progenitor (BRASIL, 2002), assim, "não é o fato da pré-morte de um dos genitores que vai afastar aprioristicamente o direito do nascido, mediante inseminação artificial póstuma, de ter consignado em sua certidão originária o nome dos pais" (ALBUQUERQUE FILHO, 2006) ainda que eventualmente um deles já esteja falecido no momento de sua concepção ou nascimento.

Portanto, em regra, o filho concebido por meio de inseminação artificial, nascido ou não após a porte do genitor, possui o direito de filiação, desde que, nos termos do artigo 1.598 do Código Civil ${ }^{21}$, nascidos dentro do prazo de 300 (trezentos) dias a contar da data do

\footnotetext{
21 “Art. 1.598. Salvo prova em contrário, se, antes de decorrido o prazo previsto no inciso II do art. 1.523, a mulher contrair novas núpcias e lhe nascer algum filho, este se presume do primeiro marido, se nascido dentro dos trezentos dias a contar da data do falecimento deste e, do segundo, se o nascimento ocorrer após esse período e já decorrido o prazo a que se refere o inciso I do art. 1597."
} 
falecimento, garantia que não abarcou integralmente os direitos sucessórios, conforme melhor exposto a frente.

\section{DAS TÉCNICAS DE REPRODUÇÃO HUMANA ASSISTIDA}

As técnicas de reprodução assistida não são tema recente, em 1978 por exemplo nasceu o primeiro bebê gerado por meio da fertilização in vitro ("bebê de proveta"), já o Brasil registrou o seu primeiro nascimento em 1984, sendo que com o passar do tempo "as investigações cientificas na área de reprodução humana assistida se propagaram e os avanços puderam ser observados em diversos países" (SCALQUETTE, 2009).

A reprodução assistida consiste naquela em que "o casal recebe orientação de forma a programar a forma de suas relações, visando a facilitação do encontro do espermatozoide com o óvulo" (SCALQUETTE, 2009), cuja assistência pode se dar de duas maneiras: aconselhamento e acompanhamento da periodicidade da atividade sexual do casal no intuito de otimizar as chances de concepção, ou por meio do emprego de técnicas médicas que interferem diretamente no ato reprodutivo e fecundação, sendo estas últimas as que repercutem e geram consequências no âmbito jurídico.

Conforme já amplamente exposto, as pessoas desfrutam de liberdade para realizar escolhas, incluindo o que diz respeito à procriação de forma artificial e a consecução do projeto de parentalidade, entretanto, essa liberdade não se mostra ilimitada, nesta busca pela realização pessoal e familiar necessariamente deve-se respeitar o princípio da dignidade humana, bem como aos princípios norteadores da bioética.

Por oportuno, cumpre salientar, que as técnicas de reprodução humana assistida variam, sendo que entre estas destaca-se a inseminação artificial homóloga, inseminação artificial heteróloga e a cessão temporária de útero, a serem individualizadas abaixo.

\subsection{DA INSEMINAÇÃO ARTIFICIAL HOMÓLOGA}

A inseminação artificial homóloga é a técnica em que se utiliza o material genético do próprio casal, onde se "manipula gametas da mulher (óvulo) e do marido (sêmen) e, cuja fecundação, substitui a concepção natural, havida por meio da cópula. O meio artificial resulta da impossibilidade ou deficiência para gerar de um ou de ambos os cônjuges" (LÔBO, 2011, p. 200).

A inseminação pode ocorrer mesmo após a morte do marido, entretanto, importante frisar que, nestes casos o projeto parental é elaborado em vida e de forma conjunta, já que de 
acordo com a Resolução n. 2.168/2017, do Conselho Federal de Medicina, em seu item VIII (CFM, 2017), os cônjuges ou companheiros deverão expressar sua pretensão, por escrito, quanto ao destino que será dado ao material biológico de reprodução criopreservado, nas hipóteses de divórcio, patologias graves ou de falecimento de um deles ou de ambos, ao passo que excepcionalmente a utilização não consentida do sêmen deve ser equiparada à do doador anônimo, o que não implica atribuição de paternidade (DANTAS, 2018, p. 33-36).

Há quem admita o consentimento de forma implícita, tácita, mas inequívoca, cujo entendimento se estende às demais hipóteses em que finda a sociedade conjugal (separação de fato, divórcio e invalidade do casamento), ou seja, para a utilização do material biológico do exmarido há a necessidade de consentimento informado e que a ex-mulher não possua outro relacionamento afetivo, sob pena da citada presunção de paternidade deixa de existir, resguardando-se ao filho o direito de promover a investigação de paternidade com base no critério biológico $^{22}$.

\subsection{DA INSEMINAÇÃO ARTIFICIAL HETERÓLOGA}

Em tal método, utiliza-se o esperma de um terceiro doador fértil, há aqui a fecundação da mulher com material de outrem, entretanto, afasta-se a paternidade do fornecedor do material genético, sendo o marido da futura gestante considerado o pai do filho concebido (DIAS, 2015, p. 335).

Nestes casos o único requisito imprescindível é a concordância do marido, não se exigindo que seja o marido estéril. Entretanto, como bem explica Guilherme Calmon Nogueira da Gama, esta espécie de procedimento costuma ser utilizado quando "um ou ambos os cônjuges ou companheiros não tenham condições de contribuir com o material genético para a fecundação" (GAMA, 2003. p. 735-736).

Importante, frisar que não obstante os estreitos limites da norma legal, na fecundação artificial heteróloga pode haver adoção de gametas de terceiro anônimo de sêmen e/ou óvulo, isso é o terceiro doador pode ser homem, mulher ou ambos.

Contudo, de acordo com o artigo 1597, inciso V do Código Civil presume-se concebido na constância do casamento o filho havido por inseminação artificial heteróloga, desde que tenha prévia autorização do marido, sendo assim o consentimento irrevogável e "jamais a paternidade

\footnotetext{
${ }^{22}$ A I Jornada de Direito Civil, do Conselho da Justiça Federal, 2002, a respeito do tema aprovou o seguinte enunciado: "interpreta-se o inciso III do art. 1.597 para que seja presumida a paternidade do marido falecido, que seja obrigatório que a mulher, ao se submeter a uma das técnicas de reprodução assistida com o material genético do falecido, esteja ainda na condição de viúva, devendo haver ainda autorização escrita do marido para que se utilize seu material genético após sua morte".
} 
pode ser impugnada pelo marido, não podendo este voltar-se contra o próprio ato, em violação da boa-fé" (LÔBO, 2011, p. 224), sob pena de caracterizar o venire contra factum proprium.

\subsection{DA MATERNIDADE SUBSTITUTIVA}

A cessão temporária de útero é também conhecida como "maternidade de substituição", ou ainda mais popularmente como "barriga de aluguel", consistindo na "cessão de útero para a gestante de filho concebido pelo material genético de terceiro - contratante - a quem a criança gerada deverá ser entregue logo após o nascimento, assumindo a fornecedora a condição de mãe" (MALUF, 2013. p. 216), viabilizando-se em linhas gerais a concepção de um filho fora do ventre da mãe biológica.

Neste caso específico, haverá a fertilização homóloga, quando forem utilizados os gametas do casal que contratou a "barriga de aluguel", ou seja, dos pais contratantes, diferentemente, da fertilização heteróloga, situação em que será utilizado gameta masculino ou feminino (ou até mesmo ambos) doados por um terceiro (geralmente anônimo).

E, embora seja a cessão um negócio jurídico, de acordo com o item VII da Resolução n. 2.168/2017 do Conselho Federal de Medicina (CFM, 2017), não pode ser esta condicionada à uma contraprestação pecuniária ou negociação comercial, sendo que a cedente deve pertencer à família de um dos parceiros em parentesco consanguíneo até o quarto grau.

\section{DOS ASPECTOS GERAIS DO DIREITO DAS SUCESSÕES}

No sentido jurídico, de acordo com o Código Civil, a palavra sucessão refere-se a um modo especial de aquisição, constitui uma transmissão universal do patrimônio de uma pessoa falecida a uma ou mais pessoas vivas, cuja a origem "vem da mais remota antiguidade, constituindo-se num prolongamento natural da família. O direito de propriedade era estabelecido para o cumprimento de um culto hereditário. Não podia extinguir-se ao cabo da curta vida do indivíduo" (QUEIROGA, 2012. p. 02).

Deste modo, o direito das sucessões pode ser entendido como o conjunto de normas que regulam a transferência do patrimônio de alguém a outro, depois de sua morte, em virtude de lei ou testamento (QUEIROGA, 2012. p. 02), tido constitucionalmente como um direito 
fundamental, nos termos do artigo $5^{\circ}$, inciso XXX da Constituição Federal $^{23}$, sendo que infraconstitucionalmente encontra respaldo nos artigos 1.784 a 2.027 do Código Civil.

\subsection{DAS ESPÉCIES DE SUCESSÃO E DA ORDEM DE VOCAÇÃO HEREDITÁRIA}

De acordo com a legislação civil (art. 1.786 do Código Civil ${ }^{24}$ ) há possibilidade de suceder por duas formas, a primeira é a sucessão legitima que consiste naquela "que decorre da lei, que enuncia a ordem de vocação hereditária, presumindo a vontade do autor da herança" (TARTUCE, 2017, p. 951), também denominada sucessão ab intestato. Já a segunda é a sucessão testamentária, no qual os efeitos decorrem do ato de última vontade do falecido que deixa testamento, legado ou codicilo (TARTUCE, 2017, p. 951).

Destaca-se que, conforme preconiza o artigo 1.788 do Código Civil ${ }^{25}$, quando a pessoa vier a morrer sem deixar testamento a herança transmitir-se-á automaticamente aos herdeiros legítimos, situação que também ocorrerá quando houver bens não compreendidos no testamento, ou ainda se este último caducar, houver rompimento ou for julgado nulo (nulidade absoluta) (NADER, 2016, p. 53).

Assim, "a ordem de raciocínio a ser seguida na sucessão é primeiro de investigar a existência de disposição de última vontade que seja válida e eficaz” (TARTUCE, 2017, p. 951), por conseguinte não havendo tal disposição, "vige a ordem de sucessão legítima" (TARTUCE, 2017, p. 951) estabelecida no artigo 1.829 do Código Civil ${ }^{26}$, chamando-se primeiramente os descendentes, na inexistência destes os ascendentes, sendo que nestas duas hipóteses o cônjuge ou companheiro concorrerá com aqueles, e na falta de ambos sucederá sozinho, já os colaterais apenas serão chamados a suceder quando inexistente todas as outras categorias citadas.

\subsection{DO MOMENTO DA ABERTURA DA SUCESSÃO}

\footnotetext{
23 “Art. $5^{\circ}$ Todos são iguais perante a lei, sem distinção de qualquer natureza, garantindo-se aos brasileiros e aos estrangeiros residentes no País a inviolabilidade do direito à vida, à liberdade, à igualdade, à segurança e à propriedade, nos termos seguintes: [...] XXX - é garantido o direito de herança".

24 “Art. 1.786. A sucessão dá-se por lei ou por disposição de última vontade".

25 “Art. 1.788. Morrendo a pessoa sem testamento, transmite a herança aos herdeiros legítimos; o mesmo ocorrerá quanto aos bens que não forem compreendidos no testamento; e subsiste a sucessão legítima se o testamento caducar, ou for julgado nulo".

26 “Art. 1.829. A sucessão legítima defere-se na ordem seguinte: I - aos descendentes, em concorrência com o cônjuge sobrevivente, salvo se casado este com o falecido no regime da comunhão universal, ou no da separação obrigatória de bens (art. 1.640, parágrafo único); ou se, no regime da comunhão parcial, o autor da herança não houver deixado bens particulares; II - aos ascendentes, em concorrência com o cônjuge; III - ao cônjuge sobrevivente; IV - aos colaterais".
} 
A abertura da sucessão dá-se com a morte real ou presumida do autor da herança, conforme previsto no artigo 1.784 do Código $\mathrm{Civil}^{27}$. Com a abertura da sucessão, há a transmissão aos herdeiros tanto da propriedade como da posse dos bens nas condições em que se achavam antes do falecimento. Fato que não se estende aos legatários, já que por disposição legal estes não fazem jus à posse indireta ${ }^{28}$, somente a assumindo após o cumprimento do legado, mas a propriedade lhes pertence com a abertura da sucessão (GONÇALVES, 2012).

É crucial para os efeitos da herança a definição do momento da morte, pois a linha de acontecimentos implicará em mais ou menos direitos aos herdeiros, assim, “[...] quando dois ou mais membros de uma família são encontrados mortos, havendo nexos sucessórios entre eles, é indispensável que se investigue a sequência dos falecimentos" (NADER, 2016, p. 56).

Contudo, nem sempre essa apuração é possível, de modo que se presumirá a comoriência, que significa a morte simultânea de duas ou mais pessoas em um mesmo acontecimento, sem hipótese de averiguação sobre qual delas morreu primeiro, conforme previsto no artigo $8^{\circ}$ do Código $\mathrm{Civil}^{29}$, neste caso nenhum dos mortos chega a herdar do outro.

Há ainda situações em que não é possível ter a certeza da morte do autor da herança, entretanto, as condições de sua ausência ${ }^{30}$ fazem presumir o seu falecimento (GONÇALVES, 2012), sendo que apenas após a decretação da morte daquele que se encontra ausente ${ }^{31}$ é realizada a abertura de sua sucessão, conforme previsto no art. $6^{\circ}$ do Código Civil ${ }^{32}$.

\subsection{DA PROLE EVENTUAL}

Quanto à capacidade de suceder, o Código Civil permite que pessoas ainda não concebidas possam ser instituídas herdeiras testamentárias, no entanto, faz duas exigências, que o testador indique a pessoa que deva conceber, e que essa pessoa esteja viva no momento da

\footnotetext{
27 “Art. 1.784. Aberta a sucessão, a herança transmite-se, desde logo, aos herdeiros legítimos e testamentários". 28 “Art. 1.923. Desde a abertura da sucessão, pertence ao legatário a coisa certa, existente no acervo, salvo se o legado estiver sob condição suspensiva. $\S 1$ o Não se defere de imediato a posse da coisa, nem nela pode o legatário entrar por autoridade própria. $\S 2^{\circ} \mathrm{O}$ legado de coisa certa existente na herança transfere também ao legatário os frutos que produzir, desde a morte do testador, exceto se dependente de condição suspensiva, ou de termo inicial."

29 “Art. 8 Se dois ou mais indivíduos falecerem na mesma ocasião, não se podendo averiguar se algum dos comorientes precedeu aos outros, presumir-se-ão simultaneamente mortos."

30 “Art. 22. Desaparecendo uma pessoa do seu domicílio sem dela haver notícia, se não houver deixado representante ou procurador a quem caiba administrar-lhe os bens, o juiz, a requerimento de qualquer interessado ou do Ministério Público, declarará a ausência, e nomear-lhe-á curador."

${ }^{31}$ O Código Civil elenca duas possibilidades: quando a pessoa, ao desaparecer, encontrava-se em perigo de vida ou quando alguém, desaparecido em campanha ou feito prisioneiro, não for encontrado até dois anos após o término da guerra.

32 “Art. 6. A existência da pessoa natural termina com a morte; presume-se esta, quanto aos ausentes, nos casos em que a lei autoriza a abertura de sucessão definitiva."
} 
abertura da sucessão, conforme expresso em seu artigo $1.799^{33}$, pois se "morrer antes da abertura da sucessão, a disposição testamentária será ineficaz” (GONÇALVES, 2012).

Enquanto na sucessão legítima designada somente podem suceder as pessoas físicas já concebidas, na sucessão testamentária admite-se tanto as pessoas físicas, quanto as jurídicas, além daquelas ainda sequer foram concebidas, pois de acordo com Guilherme Calmon Nogueira da Gama:

[...] a capacidade testamentária passiva se reveste de alguns contornos bastante particulares, permitindo, por exemplo - sob a modalidade de instituição testamentária condicional -, a disposição em favor de ente que sequer tem existência física e, simultaneamente, jurídica, como na hipótese envolvendo o filho eventual de pessoa determinada existente por ocasião do falecimento do testador (GAMA, 2007, p. 213).

No caso da prole eventual, com a morte do testador, nos termos do artigo 1.800 do Código Civil ${ }^{34}$, o patrimônio - entendido aqui como o conjunto de bens deixados pelo testador serão entregues, após a liquidação ou partilha, ao curador nomeado pelo juiz, que salvo disposição testamentária em contrário, será a pessoa cujo filho o testador pretende beneficiar.

Infere-se assim, que "aberta a sucessão que beneficia a prole eventual, a herança é posta sob administração, permanecendo nessa situação até que a condição se cumpra ou haja a certeza de que não pode cumprir-se" (GONÇALVES, 2012, p. 53), assim, nascendo com vida o herdeiro esperado, ser-lhe-á deferido a sucessão, com os frutos e rendimentos relativos a ela, a partir da morte do testador.

Salienta-se que a espera pela concepção não dura tempo indeterminado, por disposição legal, se decorridos dois anos após a abertura da sucessão não for concebido a prole os bens reservados, salvo disposição contrária do testador, serão destinados aos herdeiros legítimos.

Diante disso, forçoso reconhecer que a mãe que deseja inseminar o material genético do cônjuge ou companheiro falecido, realizando a concepção post mortem, possui o prazo de dois anos para o nascimento do filho, para que possa este usufruir do seu direito de herança, que

\footnotetext{
33 “Art. 1.799. Na sucessão testamentária podem ainda ser chamados a suceder: I - os filhos, ainda não concebidos, de pessoas indicadas pelo testador, desde que vivas estas ao abrir-se a sucessão; II - as pessoas jurídicas; III - as pessoas jurídicas, cuja organização for determinada pelo testador sob a forma de fundação." 34 "Art. 1.800. No caso do inciso I do artigo antecedente, os bens da herança serão confiados, após a liquidação ou partilha, a curador nomeado pelo juiz. § $1^{\circ}$ Salvo disposição testamentária em contrário, a curatela caberá à pessoa cujo filho o testador esperava ter por herdeiro, e, sucessivamente, às pessoas indicadas no art. 1.775. $\S$ $2^{\circ}$ Os poderes, deveres e responsabilidades do curador, assim nomeado, regem-se pelas disposições concernentes à curatela dos incapazes, no que couber. $\S 3^{\circ}$ Nascendo com vida o herdeiro esperado, ser-lhe-á deferida a sucessão, com os frutos e rendimentos relativos à deixa, a partir da morte do testador. $\S 4^{\circ} \mathrm{Se}$, decorridos dois anos após a abertura da sucessão, não for concebido o herdeiro esperado, os bens reservados, salvo disposição em contrário do testador, caberão aos herdeiros legítimos".
} 
controversamente não se dá de forma automática, deve ser resguardado pelo seu progenitor em testamento.

\section{DA FILIAÇÃO POR INSEMINAÇÃO ARTIFICIAL HOMÓLOGA POST MORTEM E DOS EFEITOS SUCESSÓRIOS}

No ordenamento jurídico brasileiro são legitimadas a suceder, as pessoas já nascidas ou concebidas até o momento da abertura da sucessão, nos termos do artigo 1.798 do Código Civil ${ }^{35}$, isso é a condição para a constatação de legitimidade sucessória passiva é a sua existência no momento da abertura da sucessão, pois como esclarece Francisco José Cahali "a herança não se transmite ao vazio, ao nada. Daí a lei exigir a existência do sucessor no momento da morte do autor da herança" (CAHALI, 2007, p. 22).

Ocorre que os avanços da medicina, a probabilidade de congelamento de embriões e a popularização das técnicas de reprodução assistida, a inseminação post mortem é uma realidade, que tem trazido à tona discussões doutrinárias acaloradas quanto à capacidade de sucessão da prole concebida após a morte do seu genitor.

A polêmica deve-se ao fato de que o embrião fecundado e não implantado, no momento do óbito de seu genitor, não se equipara ao nascituro, e ante a clareza da lei, que expressamente atribui a prole eventual apenas a capacidade para suceder na modalidade testamentária, parte da doutrina, como Maria Helena Diniz, José de Oliveira Ascensão e Sílvio Venosa, tem entendido que o filho póstumo não possui legitimação para suceder, visto que foi concebido após o óbito do pai genético e por isso é afastado da sucessão legítima ou “ab intestato" (DINIZ, 2003), assim, se não houver previsão testamentária necessariamente também não terá este direito à herança (VENOSA, 2008), sob pena de se colocar em risco a segurança jurídica.

Por outro lado, há a corrente doutrinaria que entende que a regra do artigo 1.798 do Código Civil deve ser interpretada em conjunto com o artigo 1.597, do mesmo Diploma Legal, ao passo que se há o reconhecimento da presunção de paternidade para os filhos advindos da inseminação artificial post mortem, não há razão para excluir esses indivíduos no momento da sucessão (LEITE, 2011), até porque “considerar os direitos sucessórios dos nascidos postumamente apenas na hipótese da sucessão testamentária, é negar o princípio da igualdade entre os filhos" (SOUZA; DOURADO, 2018), destacando-se aqui Maria Berenice Dias, Silmara Chinelato, Juliane Fernandes Queiroz e Carlos Roberto Gonçalves.

Aliás, como coloca Maria Berenice Dias:

35 “Art. 1.798. Legitimam-se a suceder as pessoas nascidas ou já concebidas no momento da abertura da sucessão.” 
[...] é difícil dar mais valor a uma ficção jurídica do que ao princípio constitucional da igualdade assegurada à filiação $\left(\mathrm{CF} \S 6^{\circ}\right)$. Determinando a lei a transmissão da herança aos herdeiros (CC 1.784), mesmo que não nascidos (CC 1.798) e até as pessoas ainda não concebidas (CC 1.799, I), nada justifica excluir o direito sucessório do herdeiro por ter sido concebido post mortem. Sob qualquer ângulo que se enfoque a questão, descabido afastar da sucessão quem é filho e foi concebido pelo desejo do genitor (DIAS, 2011, p. 123).

Em contrapartida, existe a discussão do lapso temporal para a concepção do filho póstumo, pois inexiste previsão de prazo para a concepção do filho advindo da reprodução humana assistida post mortem.

Diante do assunto, Eduardo de Oliveira Leite preconiza:

\begin{abstract}
Ainda e novamente, a questão que surge no caso em tela é mais de ordem sucessória do que propriamente, de parentesco ou filiação, uma vez que o recurso dos embriões excedentários, a qualquer tempo, faz ressurgir a problemática de indefinição no partilhar dos bens, o que não é desejado nem pelo sistema codificado de 16, nem pelo o atual. Melhor seria que, ao invés de se referir a qualquer tempo, contrário à partilha definitiva, o legislador tivesse estabelecido um prazo determinado (como ocorre no $\S 4^{\circ}$ do artigo 1.800 ), sem possibilidade de disposição contrária, criando assim, maior segurança jurídica e melhor possibilidade de pôr fim ao estado condominial que o nosso sistema nunca pretendeu favorecer (LEITE, 2011, p. 134-135).
\end{abstract}

Diante, da inexistência de previsão legal para a concepção do filho póstumo, surge a possibilidade de insegurança jurídica, em relação aos demais herdeiros, pois o nascimento desse filho após um longo lapso temporal, pode comprometer a herança.

Assim, como coloca Carlos Cavalcanti Albuquerque Filho cabe ao autor da sucessão fixar o prazo de espera pelo nascimento do futuro filho, por meio de testamento ou outro documento, não devendo ultrapassar o prazo de dois anos (ALBUQUERQUE FILHO, 2006, p. 188).

Apesar disso, o art. 1.800, $\S 4^{\circ}$, do Código Civil ${ }^{36}$, determina um prazo de 02 (dois) anos após a abertura do testamento, para o nascimento do filho esperado, ou outro prazo estipulado pelo autor da herança no testamento. Não sendo, esses prazos respeitados os bens reservados para o filho póstumo serão distribuídos entre os herdeiros.

Porém, a limitação de prazo para a concepção do filho não possui fundamento aceitável, pois a restrição de lapso temporal poderá acarretar discriminação do filho post mortem nascido depois do prazo de dois anos, visto que o argumento de estabelecer segurança aos demais

\footnotetext{
36 "Art. 1.800. No caso do inciso I do artigo antecedente, os bens da herança serão confiados, após a liquidação ou partilha, a curador nomeado pelo juiz. [...] § 4o Se, decorridos dois anos após a abertura da sucessão, não for concebido o herdeiro esperado, os bens reservados, salvo disposição em contrário do testador, caberão aos herdeiros legítimos."
} 
herdeiros não pode ser mais forte sobre o direito de sucessão do filho que veio a nascer, mesmo que depois do prazo de 02 (dois) anos (FERRAZ, 2016).

Com posicionamento semelhante e com respaldo em sede constitucional, Guilherme Calmon Nogueira da Gama entende que, surge problema na situação em que a criança venha nascer após o termino do inventario e da realização da partilha. Tendo como solução, a petição de herança, com a pretensão deduzida dentro do prazo prescricional de dez anos a contar do falecimento do autor da sucessão, para garantir tanto o direito do concebido póstumo e os demais herdeiros (GAMA, 2007. p. 218-219).

Entretanto, é necessário considerar o preceito constitucional do melhor interesse da criança, que por sua vez está previsto no art.227 ${ }^{37}$ da Constituição Federal, pois confere direitos aos filhos, como o direito de filiação, ao desenvolvimento e assistência. Dessa forma, retirando o direito do filho póstumo em receber a herança como os outros herdeiros, estará ferindo os princípios constitucionais. Nesta esteira, a Constituição Federal no art. 227, não admite em nenhum grau a pratica de desigualdade entre os filhos, devendo todos serem tratados de forma igualitária.

Portanto, conforme a Constituição Federal, os filhos concebidos naturalmente, por meio de inseminação artificial ou adotados, são todos iguais, com os mesmos direitos, inclusive o direito a filiação e sucessão.

Contudo, apesar da aceitação por parte dos indivíduos da concepção após a morte do pai o ordenamento jurídico brasileiro, não conseguiu assegurar direitos inerentes à sucessão aos filhos advindos de tal técnica, diante da problemática que envolve o direito de sucessão do filho nascido postumamente.

O uso do princípio do livre planejamento familiar que a Constituição Federal consagra em seu art. 226, $\S 7^{038}$, podendo o casal planejar da melhor forma a formação de sua família. Devendo o Estado, garantir proteção.

Nesse sentido, Maria Berenice Dias dispõe:

O uso das técnicas de reprodução assistida é um direito fundamental, consequência do direito ao planejamento familiar que decorre do princípio da liberdade. Impensável cercear este direito pelo advento da morte de quem manifestou a vontade de ter filhos ao se submeter às técnicas de reprodução

\footnotetext{
37 “Art. 227. É dever da família, da sociedade e do Estado assegurar à criança, ao adolescente e ao jovem, com absoluta prioridade, o direito à vida, à saúde, à alimentação, à educação, ao lazer, à profissionalização, à cultura, à dignidade, ao respeito, à liberdade e à convivência familiar e comunitária, além de colocá-los a salvo de toda forma de negligência, discriminação, exploração, violência, crueldade e opressão." (BRASIL, 1988).

38 “Art. 226. A família, base da sociedade, tem especial proteção do Estado. [...] § $7^{\circ}$ Fundado nos princípios da dignidade da pessoa humana e da paternidade responsável, o planejamento familiar é livre decisão do casal, competindo ao Estado propiciar recursos educacionais e científicos para o exercício desse direito, vedada qualquer forma coercitiva por parte de instituições oficiais ou privadas.”
} 
assistida [...] A norma constitucional que consagra a igualdade da filiação não traz qualquer exceção. Assim, presume-se a paternidade do filho biológico depois do falecimento de um dos genitores. Ao nascer, ocupa a primeira classe dos herdeiros necessários. [...] Vedar reconhecimento e direito sucessório a quem foi concebido mediante fecundação artificial post mortem pune, em última análise, o afeto, a intenção de ter um filho com a pessoa amada. Punese o desejo de realizar um sonho (DIAS, 2011, p. 123-124).

Portanto, o direito sucessório do filho póstumo, estaria assegurado diante dos princípios constitucionais. Não sendo, os direitos de filiação, livre planejamento familiar, garantia de tratamento igualitário entre os filhos, respeitados, fica evidenciado clara violação dos princípios que regem a Constituição Federal.

Isto posto, o direito à herança é um direito fundamental, disposto no art. 5, inciso XXX, da Constituição Federal ${ }^{39}$, e diante do princípio da dignidade da pessoa humana o filho advindo da inseminação artificial, possui total direito à herança, uma vez que a Constituição é norma soberana, não podendo ser contrariada, com consequência de inconstitucionalidade.

\subsection{DA NECESSIDADE DE REGULAMENTAÇÃO JURÍDICA DAS TÉCNICAS DE REPRODUÇÃO HUMANA ASSISTIDA}

Como visto, frente ao avanço da medicina e a possibilidade de procriação artificial, surgem várias lacunas no ordenamento jurídico em relação ao direito e sucessão que os concebidos post mortem possuem, em especial, no que diz respeito a falta de regulamentação jurídica específica, capaz de garantir direitos a quem submeter-se a tal procedimento e, principalmente, ao filho advindo dessas técnicas.

Nessa esteira, Maria Helena Diniz apesar de contrária as novas técnicas de reprodução assistida, alega que "[...] o jurista não poderá quedar-se inerte ante essa realidade, ficando silente diante de tão intrincada questão, nem o legislador deverá omitir-se, devendo, por isso, regulá-la, rigorosamente, se impossível foi vedá-la” (DINIZ, 2003, p. 546).

Diante, de todos os questionamentos em torno da inseminação artificial post mortem, e a falta de regulamentação por parte do legislativo, é necessário a criação de leis que dispõe sobre as regras necessárias para sanar lacunas que causam problemáticas no âmbito judiciário. Portanto, é de extrema necessidade a criação de lei especifica que regulamente todas as problemáticas que norteiam a reprodução humana assistida inclusive a sucessão póstuma.

\footnotetext{
39 “Art. $5^{\text {o }}$ Todos são iguais perante a lei, sem distinção de qualquer natureza, garantindo-se aos brasileiros e aos estrangeiros residentes no País a inviolabilidade do direito à vida, à liberdade, à igualdade, à segurança e à propriedade, nos termos seguintes. [...] XXX - é garantido o direito de herança." 
Destarte, apresentado claramente a problemática existente no ordenamento jurídico envolvendo as técnicas de reprodução humana assistida ocorridas após a morte do pai, resta comprovada a necessidade de regulamentação jurídica que o tema necessita. Isso porque, não há como se ignorar o fato de que a inseminação póstuma é prática presente na sociedade, de tal modo que a omissão ou o tratamento dúbio, tal como hoje vigente, implica em punição ao filho concebido, como ocorria com os filhos advindos de relações adulterinas e incestuosas no passado, mesmo que não tenha este qualquer culpa ou ingerência pelas escolhas de seus genitores.

\section{CONCLUSÃO}

Frente a evolução médica que proporciona a concepção de prole mesmo depois da morte do genitor, o ordenamento jurídico pátrio mostra-se inefíciente quanto à aplicação de regulamentação adequada ao avanço das técnicas de reprodução humana assistida, ao passo que as indagações que norteiam o direito sucessório do filho advindo da inseminação artificial póstuma tendem a acarretar muitas controvérsias jurídicas.

Observa-se que, ainda que o Código Civil reconheça a filiação do filho concebido mesmo após a morte do genitor, subsiste dúvida jurídica quanto à possibilidade dos efeitos sucessórios para esse filho, principalmente, no que concerne à sucessão legítima, isso é sem que haja a previsão testamentária pelo autor da herança.

Mostra-se conflitante a lógica vigente, já que a norma reconhece o direito a filiação, mas não regulamenta o direito sucessório do filho advindo da reprodução póstuma, de modo que diante a omissão legislativa, a resposta ao problema apresentado deve ser orientada a partir de preceitos constitucionais claros e imperativos, de tal forma que filho nenhum deve ser tratado de forma desigual, ou ter sua existência digna colocada em risco, até porque não tem a prole culpa pelas escolhas dos responsáveis pelo planejamento familiar.

Assim sendo, mesmo ao silêncio da lei, forçoso o reconhecimento do direito do concebido após a morte de seu genitor em participar da herança, pois independentemente da existência ou não de testamento, é filho assim como aquele concebido ainda em vida, não se justificando tratamento diverso pela lei.

Contudo, deve a segurança jurídica aqui ser observada, assim, no intuito de se afastar qualquer dúvida que paire quanto a questão, entende-se que faz-se imprescindível a regulamentação específica não apenas para consignar expressamente tal direito, mas também para definir o lapso temporal para se conceber filho por inseminação artificial homóloga post mortem, impedindo-se o cerceamento dos direitos do concepturo, sem prejuízo dos direitos e interesses dos demais herdeiros. 


\title{
HOMOLOGICAL POST MORTEM ARTIFICIAL INSEMINATION UNDER THE OPTICS OF THE RIGHT TO AFFILIATION AND SUCCESSION
}

\begin{abstract}
This research analyzed, through bibliographic review, the right to affiliation and the succession of offspring conceived by post mortem assisted human reproduction techniques, especially with regard to the possibility of qualifying as a legitimate heir to the heritage left by its creator. The Brazilian Civil Code is inconsistent on the approach about the theme, once it recognizes to these individuals the right to the presumption of parenting, but shows up silent about the capacity of succeed on the legitimate form, advocating just the succession on the testamentary modality, witch open places to doctrinal discussions, fact that contrast with the juridical safety of the succession system and the right to the equality of the offspring, among other principals of the family law. Thus, noticed the necessity of having clear rules that contemplate the succession law, aiming not to only standardize and pacify the issue, but to offer to these children full protection within the juridical order.
\end{abstract}

KEYWORDS: Succession law; Filiation; Post mortem; Human assisted reproduction; Succession.

\section{REFERÊNCIAS}

ALBUQUERQUE FILHO, Carlos Cavalcanti de. Fecundação artificial post mortem e o Direito Sucessório. In: PEREIRA, Rodrigo da Cunha (Coord.). Família e dignidade humana. São Paulo: IOB Thomson, 2006.

ALMEIDA, José Luiz Gavião de. Código civil comentado: direito das sucessões, sucessão em geral, sucessão legitima. São Paulo: Atlas, 2003.

BETIOLI, Antonio Bento. Bioética: a ética da vida. 2. ed. São Paulo: LTr, 2015.

BEVILÁQUA, Clóvis. Código Civil dos Estados Unidos do Brasil comentado. Rio de janeiro: Francisco Alves, 1917, v. 2

BOSCARO, Márcio Antônio. Direito de filiação. São Paulo: Revista dos Tribunais, 2002.

BRASIL. Código Civil dos Estados Unidos do Brasil: Lei n ${ }^{\circ} 3.071$, de $1^{\circ}$ de janeiro de 1916. Disponível em:

$<$ http://legis.senado.leg.br/legislacao/ListaTextoIntegral.action?id=75875\&norma=102644>. Acesso em: 18 jan. 2017. 


Coleção de Leis do Império. Disponível em:

<http://www2.camara.leg.br/legin/fed/decret/1824-1899/decreto-463-2-setembro-1847-560199publicacaooriginal-82833-pl.html> Acesso em: 18 jan. 2018.

. Constituição da República Federativa do Brasil: promulgada em 5 de outubro de 1988. Brasília, DF: $\quad$ Senado, $1988 . \quad$ Disponível em: $<$ http://www.planalto.gov.br/ccivil_03/constituicao/constitui\%C3\%A7ao.htm> Acesso em: 26 mar. 2018.

. Lei $n^{\circ}$ 9.263, de 12 de janeiro de 1996: Regula o $\S 7^{\circ}$ do art. 226 da Constituição Federal, que trata do planejamento familiar, estabelece penalidades e dá outras providências. Disponível em: <http://www.planalto.gov.br/ccivil_03/leis/L9263.htm>. Acesso em: 30 jul. 2018.

. Estatuto da Criança e do Adolescente: Lei Federal no 8069, de 13 de julho de 1990. Brasília, DF, 1990. Disponível em: <http://www.planalto.gov.br/ccivil_03/leis/L8069.htm> Acesso em: 26 mar. 2018.

- Lei n. 883, de 21 de outubro de 1949. Disponível em: $\overline{<\mathrm{http}: / / w w w . p l a n a l t o . g o v . b r / c c i v i l[03 / L E I S / 1930-1949 / L 0883 . h t m>~ A c e s s o ~ e m: ~} 18$ jan. 2018.

CAHALI, Francisco José. Sujeitos da Sucessão: Capacidade e Legitimidade. In: HIRONAKA, Giselda Maria Fernandes Novaes; PEREIRA, Rodrigo da Cunha (Coord.). Direito das Sucessões. 2. ed. Belo Horizonte: Del Rey, 2007.

CARDIN, Valéria Silva Galdino. Do planejamento familiar, da paternidade responsável e das políticas públicas. IBDFAM, Belo Horizonte. Disponível em: $<\mathrm{http}: / / \mathrm{www} . i b d f a m . o r g . b r / \geq$. Acesso em: 20 out. 2017.

. Reprodução humana assistida e parentalidade responsável. Birigui: Boreal, 2016.

CFM, Conselho Federal de Medicina. Resolução CFM n. 2.168/2017. 2017. Disponível em: $<$ https://sistemas.cfm.org.br/normas/visualizar/resolucoes/BR/2017/2168>. Acesso em: 05 fev. 2018.

CHIMENTI, Ricardo da Cunha; et. al. Curso de Direito Constitucional. São Paulo: Saraiva, 2004.

COMEL, Denise Damo. Do poder familiar. São Paulo: Revista dos Tribunais, 2003.

DANTAS, Eduardo. Aspectos jurídicos da reprodução humana assistida: comentários à Resolução 2.121/2015 do Conselho Federal de Medicina Rio de Janeiro: GZ, 2018.

DEIRÓ, Pedro Eunápio da Silva. Fragmentos de estudos da história da Assembléia Constituinte do Brasil. Brasília: Senado Federal, 2006.

DIAS, Maria Berenice. Manual de Direito das Família. 10. ed. São Paulo: Revista dos Tribunais, 2015.

DINIZ, Maria Helena. Curso de Direito Civil Brasileiro: direito de família. 17. ed. São Paulo: Saraiva, 2002. 
2003.

. Curso de Direito Civil Brasileiro: direito das sucessões. 17. ed. São Paulo: Saraiva,

FERRAZ, Ana Claudia Brandão de Barros Correia. Reprodução humana assistida e suas consequências nas relações de família: a filiação e a origem genética sob a perspectiva da repersonalização. 2. ed. Curitiba: Juruá, 2016.

FRANÇA, Genival Veloso de. Direito médico. 14. ed. Rio de Janeiro: Forense, 2017.

GAMA, Guilherme Calmon Nogueira. A nova filiação e as relações parentais: o estabelecimento da parentalidade-filiação e os efeitos jurídicos da reprodução assistida heteróloga. Rio de Janeiro: Renovar, 2003.

. Capacidade para testar, para testemunhar e para adquirir por testamento. In: HIRONAKA, Giselda Maria Fernandes Novaes; PEREIRA, Rodrigo da (Coord.). Direito das Sucessões. 2. ed. Belo Horizonte Del Rey, 2007.

GONÇALVES, Carlos Roberto. Direito civil brasileiro: direito das sucessões. São Paulo: Saraiva, 2012, v. 7

HIRONAKA, Giselda Maria Fernandes Novaes. Direito das Sucessões. 2. ed. Belo Horizonte: Del Rey, 2007.

LEITE, Eduardo de Oliveira. Estudos de Direito de Família e pareceres de Direito Civil. Rio de Janeiro: Forense, 2011.

LÔBO, Paulo. Direito civil: famílias. 4. ed. São Paulo: Saraiva, 2011.

. Código Civil Comentado: direito de família. Relações de parentesco. In: AZEVEDO, Alvaro Vilaça (Coord.). Direito Patrimonial. São Paulo: Atlas, 2003.

MADALENO, Rolf. Filhos do coração. Revista brasileira de direito de família - IBDFAM, Porto Alegre, v. 6, n. 23, abr./maio 2004.

MALUF, Adriana Caldas do Rego Freitas Dabus. Curso de bioética e biodireito. 2. ed. São Paulo: Atlas, 2013.

MOURA, Mario Aguiar. Tratado Prático da Filiação. Rio de Janeiro: Aide, 1987, v. 3.

NADER, Paulo. Curso de direito civil: direito das sucessões. 7. ed. Rio de Janeiro: Forense, 2016, v. 6 .

PEREIRA, Caio Mário da Silva. Instituições de Direito Civil. 20. ed. Rio de Janeiro: Forense, 2012.

QUEIROGA, Antônio Elias de. Curso de Direito Civil: Direito das Sucessões. 2. ed. Rio de Janeiro: Renovar, 2012.

RODRIGUES, Silvio. Direito Civil. 27. ed. São Paulo: Saraiva, 2002. 
SCALQUETTE, Ana Cláudia Silva. Estatuto da Reprodução Assistida. Tese (Doutorado em Direito Civil). Universidade de São Paulo, 2009. Disponível em: $<$ www.teses.usp.br/teses/.../Tese_Ana_Claudia_Silva_Scalquette_versao_simplificada.pdf $>$. Acesso em: 30 jul. 2018.

SILVA, Diego Rodrigues. O direito sucessório dos inseminados post mortem em face dos principios constitucionais. Disponível em: $<$ https://www.jurisway.org.br/v2/dhall.asp?id_dh=11866>. Acesso em: 28 jul. 2018.

SILVA, José Afonso da. Curso de direito constitucional positivo. 30. ed. São Paulo: Malheiros, 2007.

SOUSA, Ivan Oliveira de; BRITO, Deborah Cristiane Domingues. Paternidade Presumida. Revista Linhas Jurídicas (UNIFEV), v. 3, n. 3, 2011, p.130 - 135. Disponível em: $<$ http://periodicos.unifev.edu.br/index.php/LinhasJuridicas/article/viewFile/51/45>. Acesso em: 28 jul. 2018.

SOUZA, Antonio Carlos Marques de; DOURADO, Claudina. A capacidade sucessória na inseminação artificial homóloga post mortem. Disponível em: $<$ revistaadmmade.estacio.br/index.php/e-revistafacitec/article/view/3160/1435>. Acesso em: 31 jul. 2018.

TARTUCE, Flávio. Manual de Direito Civil. 2. ed. São Paulo: Método, 2012.

. Manual de Direito Civil. 7. ed. Rio de Janeiro: Forense; São Paulo: Método, 2017.

. Novos princípios do Direito de Família brasileiro. Revista Jus Navigandi. Teresina, ano 11, n. 1069, jun. 2006. Disponível em: $<$ https://jus.com.br/artigos/8468>. Acesso em: 11 ago. 2018.

VENOSA, Sílvio de Salvo. Direito Civil: direito de família. 8. ed. São Paulo: Atlas, 2008.

WELTER, Belmiro Pedro. Igualdade entre as filiações biológica e socioafetiva. São Paulo: Revista dos Tribunais, 2003.

Trabalho enviado em 20 de dezembro de 2018

Aceito em 14 de março de 2019 